Research Article

\title{
Simulation and Experimental Study on Rotor System Dynamic Analysis with the Blade-Coating Rubbing Faults
}

\author{
Xin Lu $(\mathbb{D}$, Jie Tang $(\mathbb{D}$, and Liwen Wang $(\mathbb{D}$ \\ Tianjin Key Laboratory for Civil Aircraft Airworthiness and Maintenance, Civil Aviation University of China, \\ Tianjin 300300, China \\ Correspondence should be addressed to Liwen Wang; wlw2885@163.com
}

Received 12 April 2021; Accepted 16 August 2021; Published 11 September 2021

Academic Editor: Francesco Pellicano

Copyright (C) 2021 Xin Lu et al. This is an open access article distributed under the Creative Commons Attribution License, which permits unrestricted use, distribution, and reproduction in any medium, provided the original work is properly cited.

In the modern turbo-machinery, reducing the clearance between the blade tip and casing inner face is an effective method to improve the power performance, but the clearance reduction leads to increased risk of blade-casing rubbing. In this paper, a bladecoating rubbing force model which considered the abradable coating scraping is developed to simulate the rotor system dynamic characteristics at blade-casing rubbing faults with abradable coating. An experimental tester is established to simulate the rotor system blade-casing rubbing faults; the AlSi-ployphenyl ester abradable coating is prepared and introduced into the blade-casing experiment to verify the model. After the vibration and force analysis in simulation and experiment, the dynamic characteristics and the influence factors of blade-casing rubbing rotor system are studied.

\section{Introduction}

With the development of aircraft, decreasing the blade tip and casing inner face clearance is one of the key measures to improve the aero-engine performance. However, the reduction of tip clearance improves the probability of the rubbing fault occurring in machinery. Currently, abradable coating sprayed on the casing inner face [1] has been used in turbo-machinery to avoid the rigid blade-casing rubbing, the serious accident can be decreased or avoid. When the rubbing fault occurs, it will greatly affect the performance of the turbo-machinery.

Recently, many scholars have done lots of researches on the dynamic characteristic of the rotor system under bladecasing rubbing fault and obtained great achievement on this issue [2-7]. However, most of the literature mainly focuses on the dynamic characteristics of the system under the blade-uncoated casing rubbing fault. Research on sealing coating mainly focuses on the scraping process, and the research on its influence on the dynamic characteristics of the system is insufficient. When the rubbing fault occurs, the abradable coating is firstly in contact with the blade and scraped by the blade. The scraping process involves a variety of physical phenomena such as rubbing impact, heat transfer, friction, and coating wear. In order to identify the fault accurately and avoid serious rubbing fault, it is essential to develop some mathematical models to reproduce the rubbing and wear processes and elucidate the blade-tip rubbing and coating wear mechanisms [8]. The initial tip between casing and blade had great influence on blade vibration amplitude in the wear process of coating. Nyssen and Batailly [9] investigated the thermal numerical model within the abradable coating in contact interactions and compared simulation and experiment data and studied the thermal impact effects on the dynamic characteristic of blade. Xue et al. [10] studied the material transfer behavior and the change of coating morphology of sealing coating at different scraping line speeds by high speed scraping machine and analyzed the causes of different wear behaviors of coating. Martinet et al. [11] developed a specific ballistic bench to thermal effect on abradable coating wear mechanisms. Based on Legrand's model, Batailly et al. [12] simulated a rotor/ stator interaction casing and found when coating material was deposited over the casing, the interaction phenomenon is highly affected by a global casing deformation, blade physical dimension, and coating properties. Batailly and Legrand [13] studied the structural behavior of a high- 
pressure compressor blade at the neighborhood of a critical rotational frequency with the interaction of abradable coating and discovered that a nonsynchronization of blade vibration caused the low vibration amplitude and the effects of the initial clearance on the blade vibration response near a critical rotating frequency. On the basis of the simulation of such interaction accounting for centrifugal stiffening and the abradable coating removal, Batailly et al. [14] emphasized that iterated profile advantageously induces to a great drop of the maximum blade static stress. Almeida et al. [15] used FE model to simulated blade-casing rubbing with coating. In their model, coating wear are formulated using Coulomb's and Archard's laws. Other scholars established the rubbing model which neglected the metal machining; Salvat et al. [2] studied the abradable coating removal cutting process on the basis of delay differential equations of this model. Based on the cluster treatment of characteristic roots (CTCR), Olgac et al. [16] used apologizing the rubbing dynamics with machine tool chatter to analyze the stability of the rotor system with blade-casing rubbing and found CTCR can declare the complete stable outlook of such time-delayed systems in the space of the operational and design parameters. Agrapart et al. [17] proposed a new insight on the blade-tip/casing rubbing simulation events considering thermomechanical effects within the casing and investigated competition between wear and thermal expansion, whereas studies on blade-coating rubbing mainly focused on the wear behavior of coating; there is little study on the rotor dynamics at blade-casing rubbing faults with abradable coating and its influence factors. Thus, it is necessary to study the dynamic characteristics of the rotor system with bladecasing rubbing faults considering abradable coating and analyze the influence factors to the dynamic characteristics.

In this paper, a rotor system model with blade-casing rubbing fault which considered the abradable coating scraping process is established and an experimental tester is established to make the verification of rubbing fault model. After simulation and experimental researches, vibration and rubbing force variation law are obtained; the influence of speed and clearance to the rotor system dynamic characteristics are analyzed.

\section{Dynamic Model}

2.1. Rotor System Model. The system is developed on the basis of a Jeffcott model symmetrically supporting on bearings, as showed in Figure 1. The bearing supporting force model and blade-casing rubbing with coating force model are considered in this rotor model.

The dynamic system vibration equations are derived as follows [18]:

$$
\left\{\begin{array}{l}
m_{r} \ddot{x}_{r}+c \dot{x}_{r}+k\left(x_{r}-x_{A}\right)+k\left(x_{r}-x_{B}\right)=m_{r} e \omega^{2} \cos \theta-F_{P, x} \\
m_{r} \ddot{y}_{r}+c \dot{y}_{r}+k\left(y_{r}-y_{A}\right)+k\left(y_{r}-y_{B}\right)=m_{r} e \omega^{2} \sin \theta-F_{P, y}-m_{r} g \\
m_{A} \ddot{x}_{A}+c_{o} \dot{x}_{A}+k\left(x_{A}-x_{r}\right)=F_{A(b, x)} \\
m_{A} \ddot{y}_{A}+c_{o} \ddot{y}_{A}+k\left(y_{A}-y_{r}\right)=F_{A(b, y)}-m_{A} g \\
m_{B} \ddot{x}_{B}+c_{o} \dot{x}_{B}+k\left(x_{B}-x_{r}\right)=F_{B(b, x)}, \\
m_{B} \ddot{y}_{B}+c_{o} \ddot{y}_{B}+k\left(y_{B}-y_{r}\right)=F_{B(b, y)}-m_{B} g
\end{array}\right.
$$

where $m_{r}, m_{A}$, and $m_{B}$ are the lumped masses of the rotor at the disk and the shaft at bearing positions, respectively, $c$ and $c_{o}$ are the disk viscous damping factors and the bearing, respectively, $k$ is the stiffness of the shaft, $F_{A}(b, x)$, $F_{A(b, y)}, F_{B}(b, x)$, and $F_{B(b, y)}$ are the bearings supporting forces, and $F_{p, x}$ and $F_{p, y}$ are the blade-coating rubbing forces.

2.2. Ball Bearing Model. The sketch of the ball bearing is shown in Figure 2. The effect of the lubrication oil between ball and race is considered on the basis of the Hertz contact theory. Regarding the point-contact, the oil film thickness equation is appropriate for the ball bearing:

$$
H_{b}=2.69 U^{0.67} G^{0.53} W^{-0.067}\left[1-0.61 \exp \left(-0.73 e_{b}\right)\right]
$$

where $U=\mu_{\mathrm{b}} u / 2 E^{\prime} R_{\mathrm{b}}$ is a nondimensional velocity, $G=\alpha E^{\prime}$ is a nondimensional material parameter, $W=Q_{\mathrm{b}} / E^{\prime} R_{\mathrm{b}}^{2}$ is a nondimensional load parameter, $e_{b}$ is the ellipticity of the rolling element, $E^{\prime}=E /\left(1-v^{2}\right)$ is the equivalent Young's modulus, $v$ is the Poisson's ratio, and $\alpha$ is the pressureviscosity coefficient.

Then, the oil film stiffness between the roller and the inner race can be calculated as 


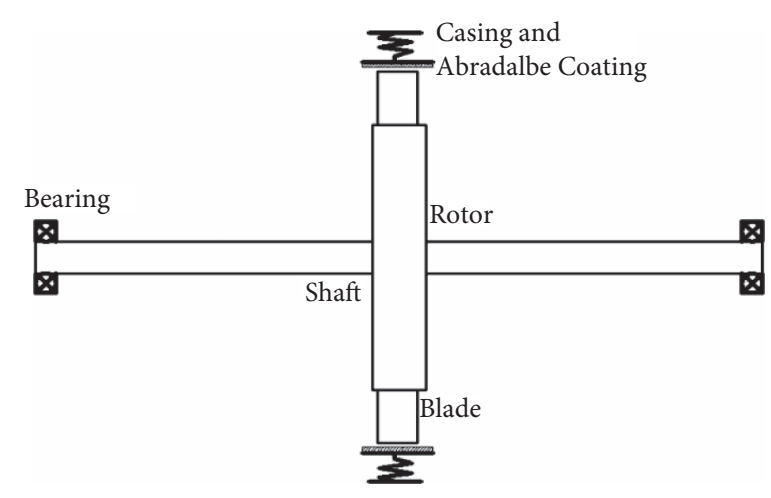

Figure 1: The model of the rotor-bearing system.

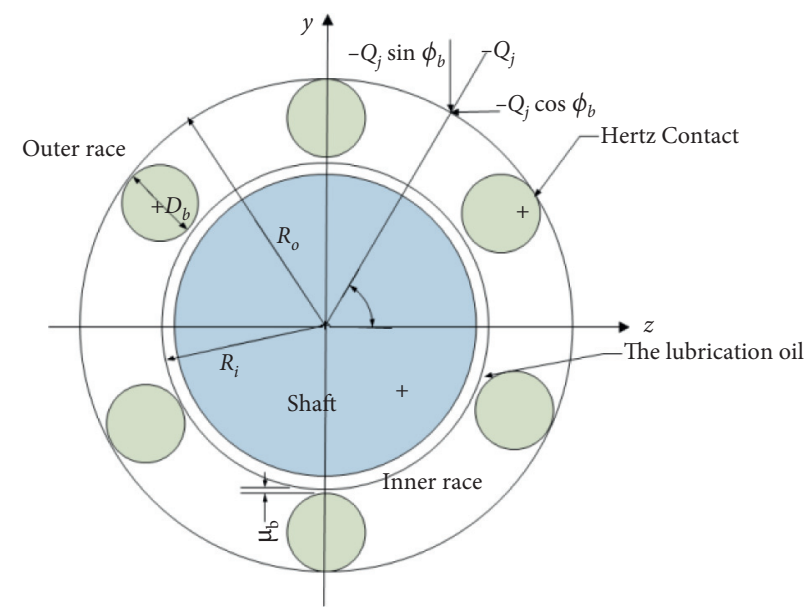

FIgURE 2: Schematic diagram of the ball bearing.

$$
\begin{aligned}
k_{\mathrm{EHL}}^{i} & =\frac{\partial Q_{j}}{\partial H_{b}^{i}} \\
& =\left(\frac{\partial H_{b}^{i}}{\partial Q_{j}}\right)^{-1} \\
& =-\frac{1}{0.18023} \bar{U}^{-0.67} \bar{G}^{-0.53} Q_{j}^{1.067} E^{\prime^{-0.067}} R_{b}^{i-1.134}\left(1-0.61 e^{-0.73 K_{\text {eli }}}\right)^{-1} .
\end{aligned}
$$

The oil film stiffness between the roller and the outer race $k_{\mathrm{EHL}}^{o}$ can be calculated in the same way. Thus, the total oil film stiffness of the bearing can be obtained:

$$
k_{b, j}^{E}=\left(\frac{1}{k_{\mathrm{EHL}}^{i}}+\frac{1}{k_{\mathrm{EHL}}^{o}}\right)^{-1} .
$$

The global stiffness of the roller can be obtained:

$$
k_{b, j}=\left(\frac{1}{k_{b, j}^{H}}+\frac{1}{k_{b, j}^{E}}\right)^{-1} .
$$

Accordingly, the supporting forces of the ball bearing in the $y$ - and $x$-directions are given as

$$
\left\{\begin{array}{l}
F_{b, y}=-Q_{b} \frac{y}{\delta_{b}} \\
=k_{b, j} \cdot \delta_{b, j} \cdot \frac{y}{\delta_{b}}, \\
F_{b, x}=-Q_{b} \frac{x}{\delta_{b}} \\
=k_{b, j} \cdot \delta_{b, j} \cdot \frac{x}{\delta_{b}} .
\end{array}\right.
$$


2.3. Blade-Casing Rubbing with Coating. The effects of the number of blades and the clearance between blade tip and casing on the rubbing force should be considered in the blade-casing rubbing model.

The schematic of the rotor, blade, and casing is shown in Figure 3; the interaction between blade and abradable coating is shown in Figure 4. Assuming $x$ and $y$ are the displacements of the rotor and disks in the $x$ - and $y$-directions, the displacements of the $i^{\text {th }}$ blade tip can be calculated as

$$
\left\{\begin{array}{l}
x_{b t i}=x+\left(R_{b}+R_{c}\right) \cos \alpha_{i}, \\
y_{b t i}=y+\left(R_{b}+R_{c}\right) \sin \alpha_{i},
\end{array}\right.
$$

where $R_{b}$ is the length of blade, $R_{c}$ is the radius of rotor, and $\alpha_{i}$ is the angle of the $i^{\text {th }}$ blade. The radial displacement of blade tip can be calculated as

$$
\eta_{i}=R_{b}+R_{c}+\delta-\sqrt{x_{b t i}^{2}+y_{b t i}^{2}}
$$

where $\delta$ is the initial clearance between the casing and blade tip.

The process of blade rub against abradable coating is different from the blade-casing rubbing without coating due to the coating's abradability. Small coating particles are removed because of the blade scraping which is similar to metal machining. The schematic of the scraped coating is shown in Figure 4. Based on Kascak and Tomko's [19] assumption, the normal and tangential force can be obtained as

$$
\begin{gathered}
\left\{\begin{array}{l}
F_{n i}=k_{c} \eta_{i}, \\
F_{t i}=\eta_{i} U b,
\end{array}\right. \\
k_{c}=\mathrm{A}_{b}(E / h)_{\text {abradable }},
\end{gathered}
$$

where $b$ is the blade width, $U$ is the abradable coating scraping energy, $k_{c}$ is the casing stiffness, $A_{b}$ is the blade cross-sectional area, $E$ is the abradable coating's Young's modulus, and $h$ is the abradable coating thickness. The abradable coating's Young's modulus can be obtained by the experiment in Section 4.

The scraping energy represents the abradability of the abradable coating, which is shown in Figure 5 [20]. It is found that the scraping energy of M601 changes a little with the development of incursion depth. The value of M601 scraping energy is assumed as $5.3 \mathrm{e} 7 \mathrm{~J} / \mathrm{m}^{3}$.

The rubbing force of one blade in the $x$-and $y$-directions can be calculated as

$$
\left\{\begin{array}{l}
F_{x i}=-F_{n i} \cos \alpha_{i}+F_{t i} \sin \alpha_{i}, \\
F_{y i}=-F_{n i} \sin \alpha_{i}-F_{t i} \cos \alpha_{i} .
\end{array}\right.
$$

Summing the rubbing force components in the $x$-and $y$ directions correspondingly, one can obtain

$$
\left\{\begin{array}{l}
F_{p, x}=\sum_{i=1}^{n} F_{x i}, \\
F_{p, y}=\sum_{i=1}^{n} F_{y i} .
\end{array}\right.
$$

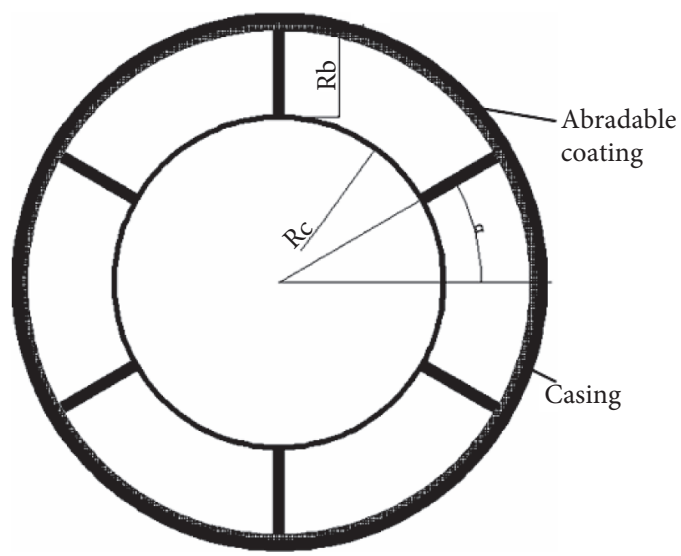

FIGURE 3: Schematic of the rotor, blade, and casing.

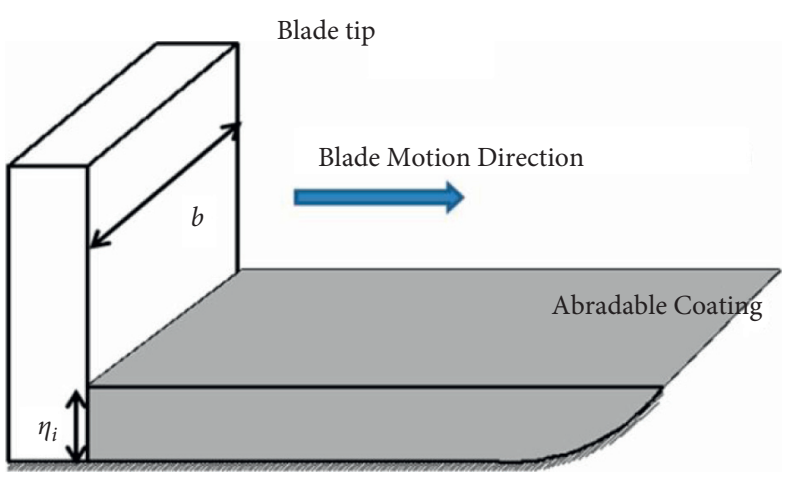

FIgURE 4: Schematic of the scraped coating.

2.4. Numerical Method and Simulation Parameters. In the paper, the differential equations of motion are solved by the Runge-Kutta method. The time step of the iterative procedure is $\Delta t=1 \times 10^{-5} \mathrm{~s}$. The time varying data corresponding to the first 500 periods generated by the numerical integration are deliberately excluded in order to discard the transient solutions. The parameters of the system and abradable coating are shown in Table 1.

\section{Simulation Result and Discussion}

3.1. Effect of Clearance. Figure 6 shows the spectrum cascades of blade-coating rubbing rotor system at different clearances; it is shown that the fundamental frequency and 2-fundamental frequency are the main frequencies of the rotor; some high integer frequencies (3-fundamental frequency, 4-fundamental frequency, 5-fundamental frequency, 6-fundamental frequency, and 7-fundamental frequency) are also affected with the development of clearance. In Figure 7 , the fundamental frequency amplitude increases linearly with the development of clearance, 2-fundamental frequency amplitude decreases linearly with the development of clearance, the fundamental frequency amplitude increases linearly from $1.438 e-5 \mathrm{~m}$ to $1.795 e-5 \mathrm{~m}$ with the clearance from $2 e-7 \mathrm{~m}$ to $1 e-5 \mathrm{~m}$, and the 2 -fundamental frequency decreases linearly from $2.642 e-6 \mathrm{~m}$ to $1.716 e-6 \mathrm{~m}$. The high integer frequencies change nonlinearly with the development of 


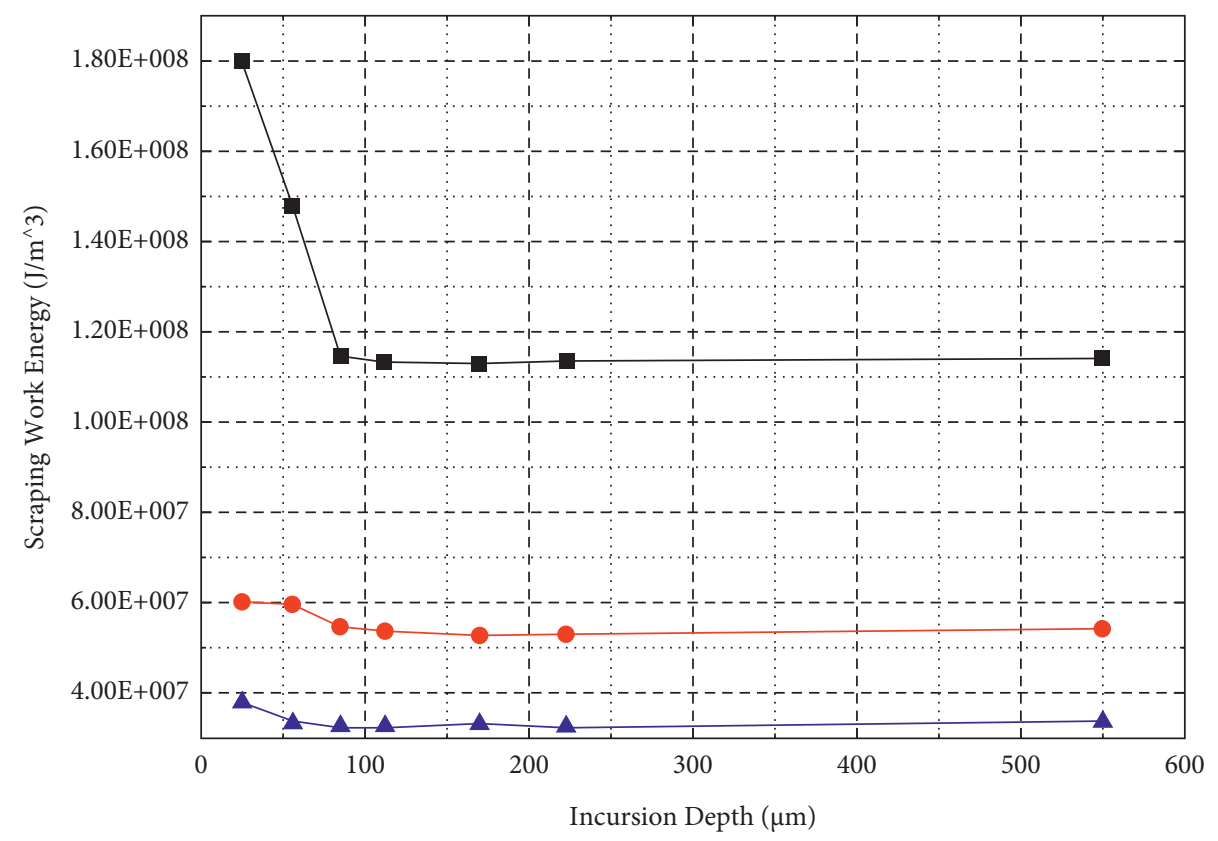

$\rightarrow$ M313 AlSi55-graphite45

- M601 AlSi60-polyester40

- M307 Ni75-graphite25

FIGURE 5: Variation of the scraping work energy with incursion depth.

TABLE 1: Parameters of the system.

\begin{tabular}{lc}
\hline$m_{r}$ & $6.7 \mathrm{~kg}$ \\
$m_{A}$ & $1 \mathrm{~kg}$ \\
$m_{B}$ & $1 \mathrm{~kg}$ \\
$c_{o}$ & $300 \mathrm{~N}^{*} \mathrm{~s} / \mathrm{m}$ \\
$c$ & $300 \mathrm{~N}^{*} \mathrm{~s} / \mathrm{m}$ \\
$k$ & $2.5 e 7 \mathrm{~N} / \mathrm{m}$ \\
$A_{b}$ & $5000 \mathrm{~mm}^{2}$ \\
$h$ & $2 \mathrm{~mm}$ \\
$b$ & $0.08 \mathrm{~m}$ \\
$U$ & $5.3 e 7 \mathrm{~J} / \mathrm{m}^{3}$ \\
$E_{\text {abradable }}$ & $2.5 \mathrm{GPa}$ \\
$v$ & 0.3 \\
$R_{b}$ & $4.7 e-2 \mathrm{~m}$ \\
\hline
\end{tabular}

clearance, 3-fundamental frequency amplitude increases with the development of clearance, 4-, 6-, and 7-fundamental frequency amplitudes decrease with the development of clearance, and 5-fundamental frequency amplitude is fluctuant with the development of clearance.

The vibration of blade-coating rubbing rotor system at different initial clearances is shown in Figure 7. It is found that there are several peaks appearing on wave crest of vibration, whether the wave trough has one peak on the time domain map, and the axis orbit has several wave peaks; it is found that the blade-coating rubbing axis orbit oscillation is relatively stable compared with the bladecasing rubbing without abradable coating [21]. With the initial clearance development, the rotor system axis orbit range is increased, the amplitude of vibration is also increased, and the vibration waveform is closed to sinusoid.
3.2. Effect of Rotational Speed. Figure 8 shows the spectrum cascades of blade-coating rubbing rotor system change with speed, with the development of speed, the fundamental frequency, and 2-fundamental frequency amplitude are increased linearly and rapidly; some high integer frequency (3-fundamental frequency, 4-fundamental frequency, 5fundamental frequency, 6-fundamental frequency, and 7fundamental frequency) amplitudes are increased nonlinearly and slowly; it is found that the blade-coating rubbing is not violent compared with the blade-casing rubbing without abradable coating [20].

Figure 9 shows the vibration of blade-coating rubbing rotor system at different speeds. With the speed increasing, the peaks on the time domain diagram become more obvious. With further increasing of speed, the number of peaks reduced to one in one vibration period; the vibration amplitude increases greatly. The results show that with the development of speed, the rotor system axis orbit range is increased too much for the centrifugal force and unbalance; the number of deflections decreases on chart of axes track, but the deflection amplitude increases, which indicates that the rubbing degree of the system is deepened.

Figure 10 shows the variation of the peak value of the rubbing force with the rotation speed and the initial clearance. It is found that from the analysis that at different initial clearances of rotor and stator, the nonlinearity of the rubbing force increases rapidly with the increase of the rotating speed; the increase amplitude is also increased with the speed development. At the same speed, the rubbing force increases slowly and linearly with the increase of the initial 


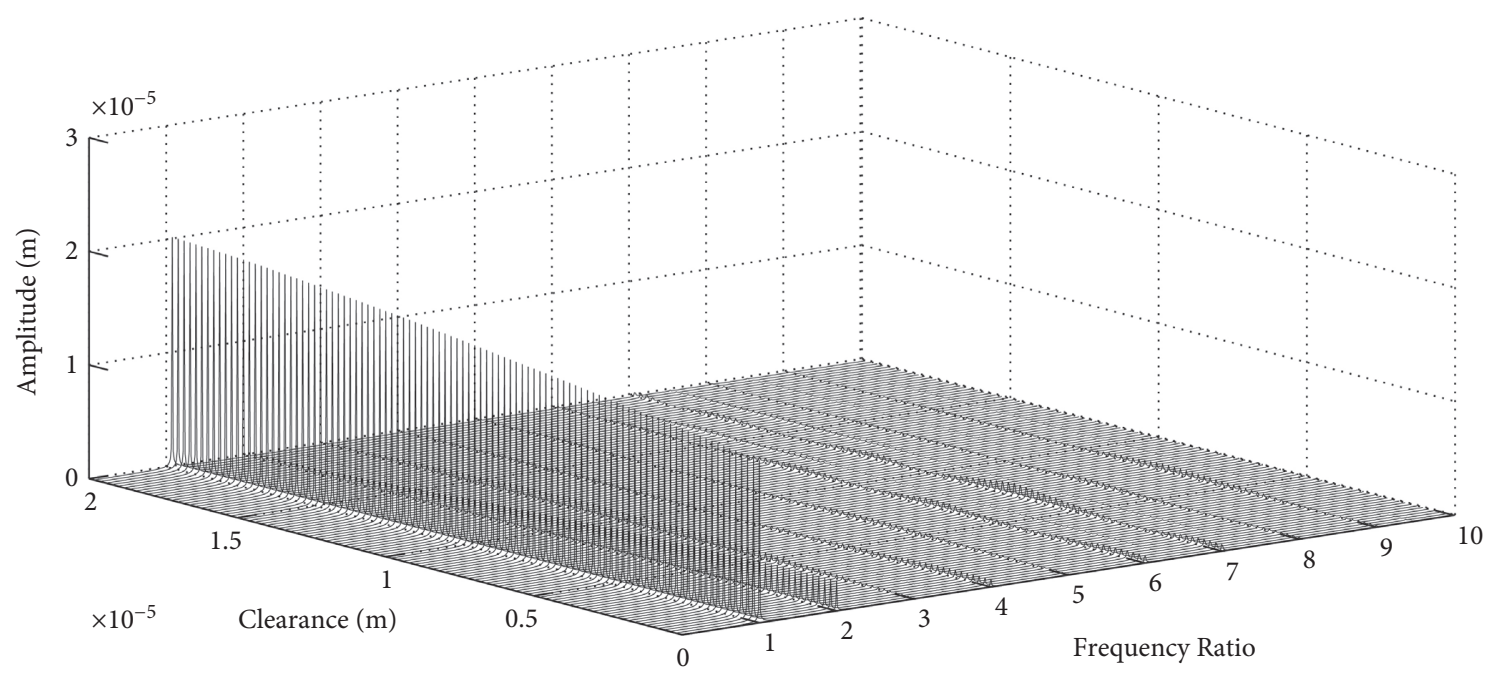

FIgURE 6: Spectrum cascades of blade-coating rubbing with clearance.
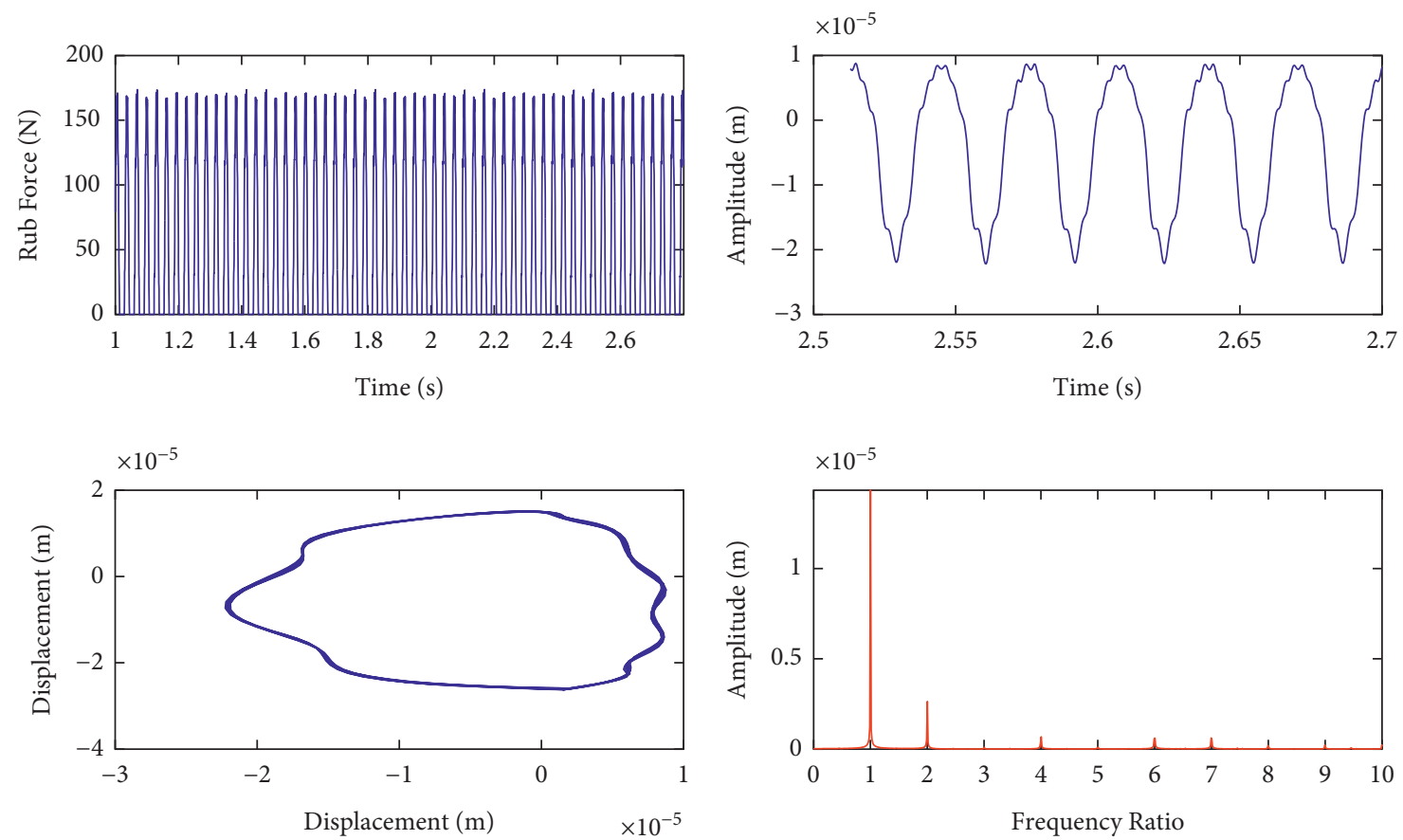

(a)

Figure 7: Continued. 

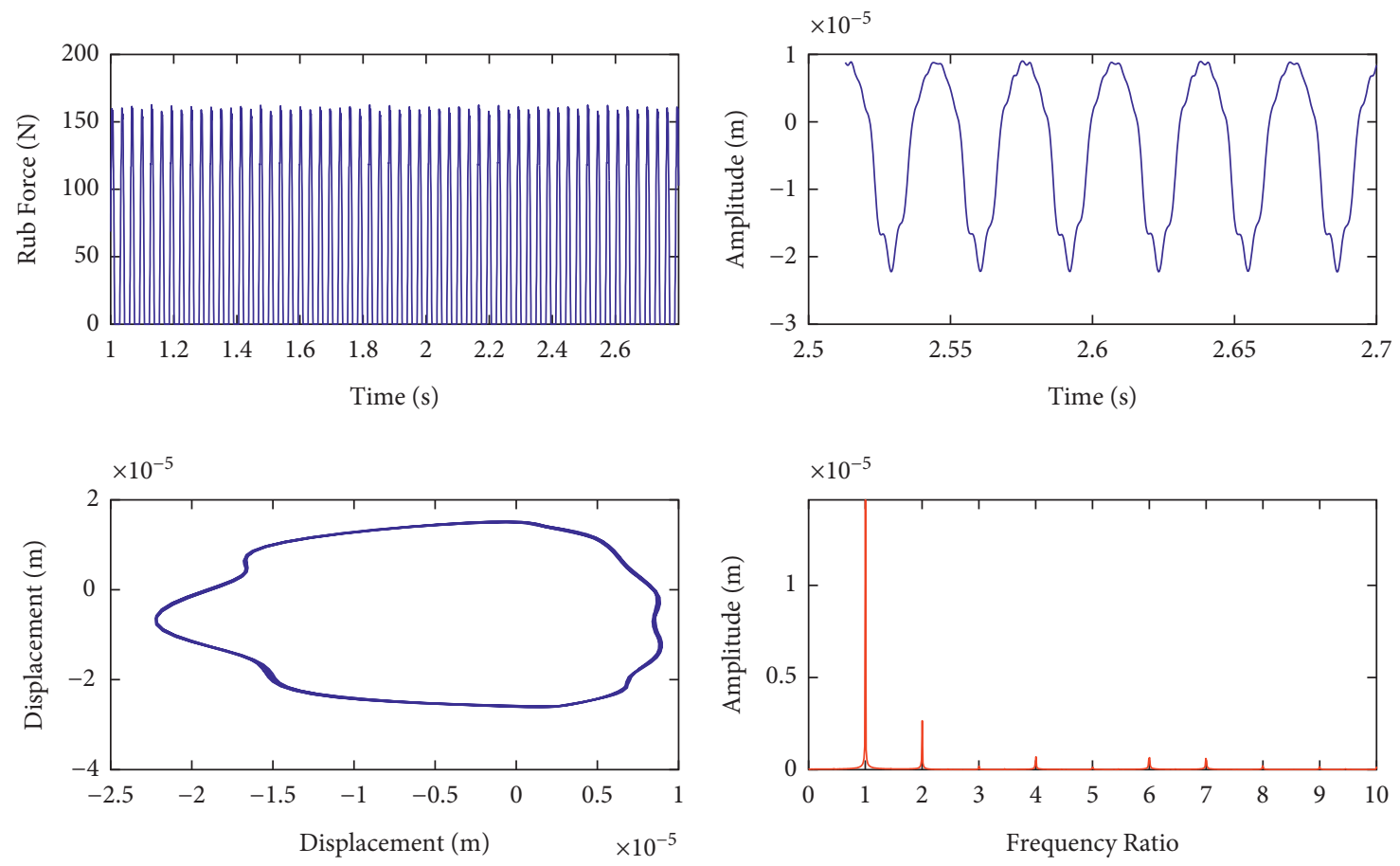

(b)
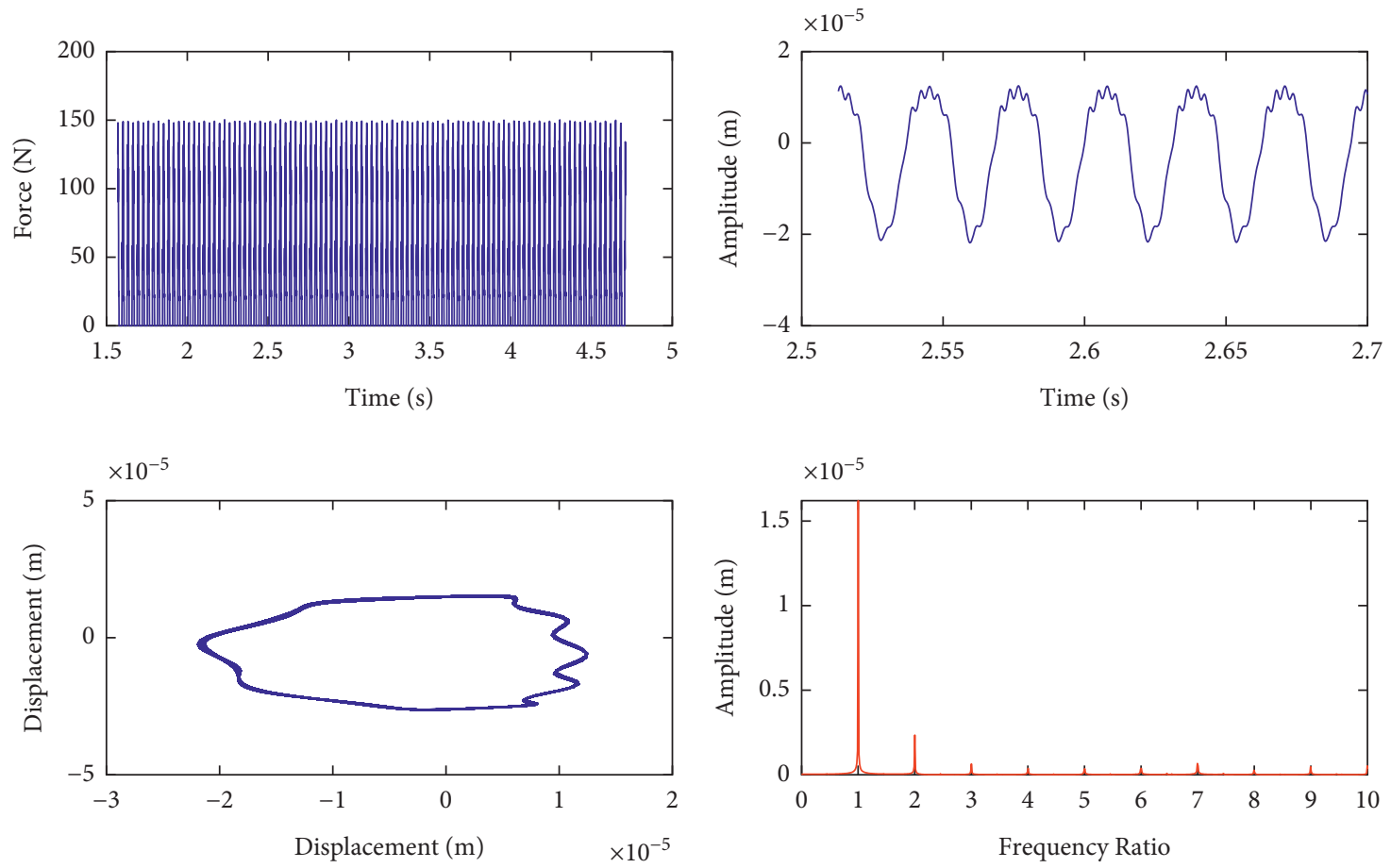

(c)

Figure 7: Continued. 

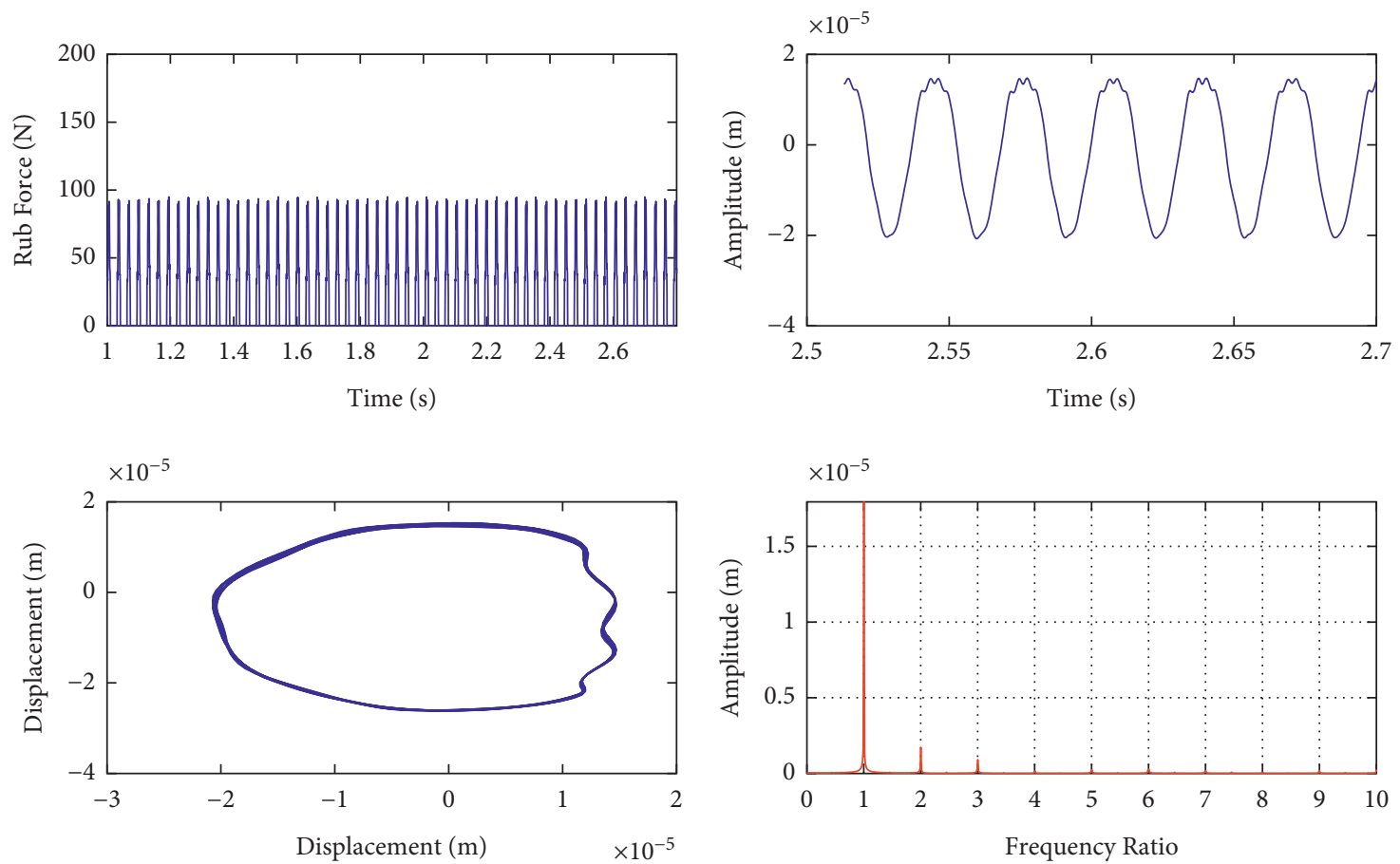

(d)

Figure 7: Vibration response of the blade-coating rubbing system at different clearances between blade tip and casing: (a) clearance $1 e-7 \mathrm{~m}$; (b) clearance $9 e-7 \mathrm{~m}$; (c) clearance $5 e-6 \mathrm{~m}$; (d) clearance $1 e-5 \mathrm{~m}$.

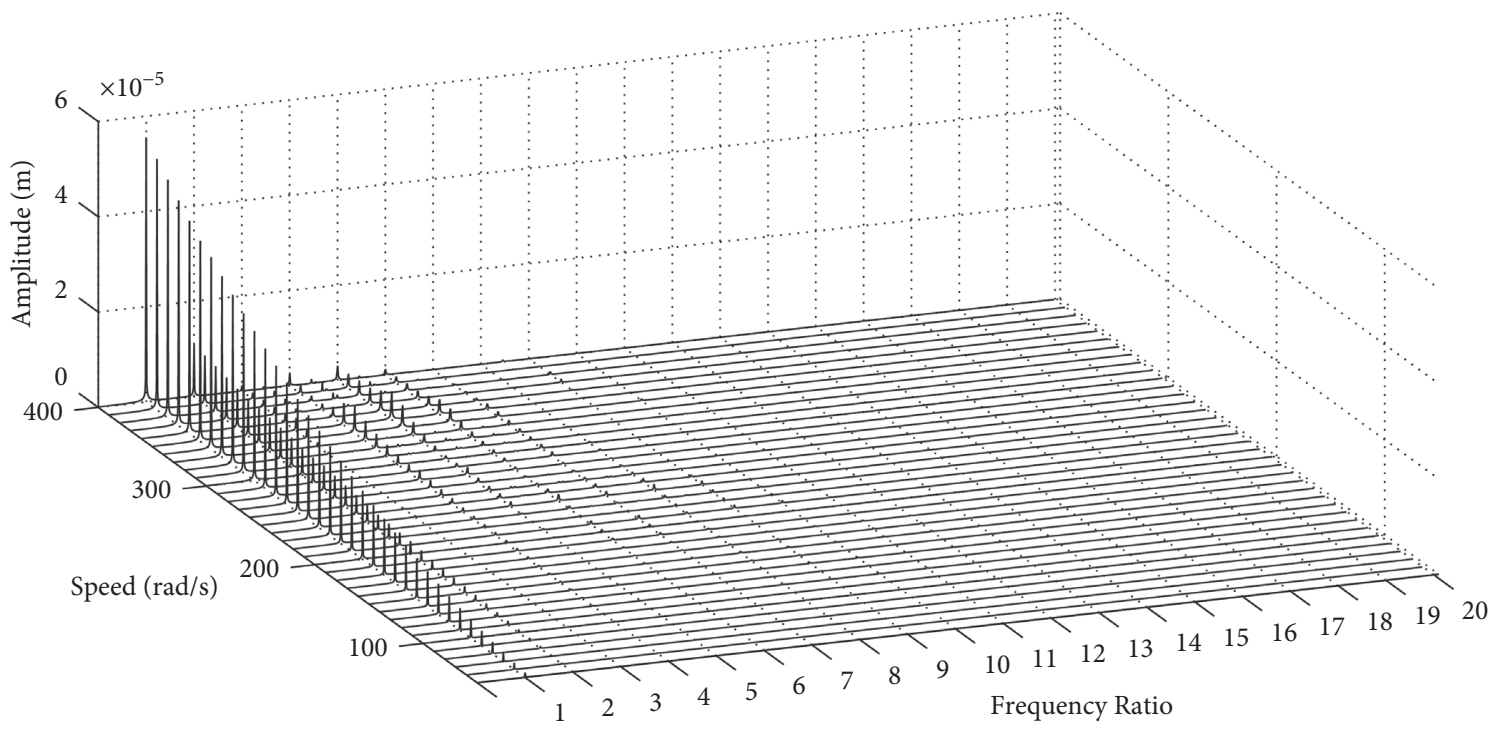

FIGURE 8: Spectrum cascades of blade-coating rubbing with speed.

clearance; the rubbing force has different variation laws on clearance at different speeds. The comparative analysis shows that the variation law of the peak value of the rubbing force is similar to that of the high multiple integer frequency. Therefore, the main frequency of blade seal coating rubbing is integer frequency. At high speed, the unbalance of the system is dominant and the rub impact characteristics have little influence.

\section{Result and Discussion of the Blade-Coating Rubbing Experimental}

4.1. Establishment of the Rubbing Experimental Test Rig. A test facility on the structure of a Jeffcott rotor system is shown as Figure 11. Ball bearings were used to support the rotor system; the rotor system was drove by motor. To simulation the blade-coating rubbing fault, a feeding device 

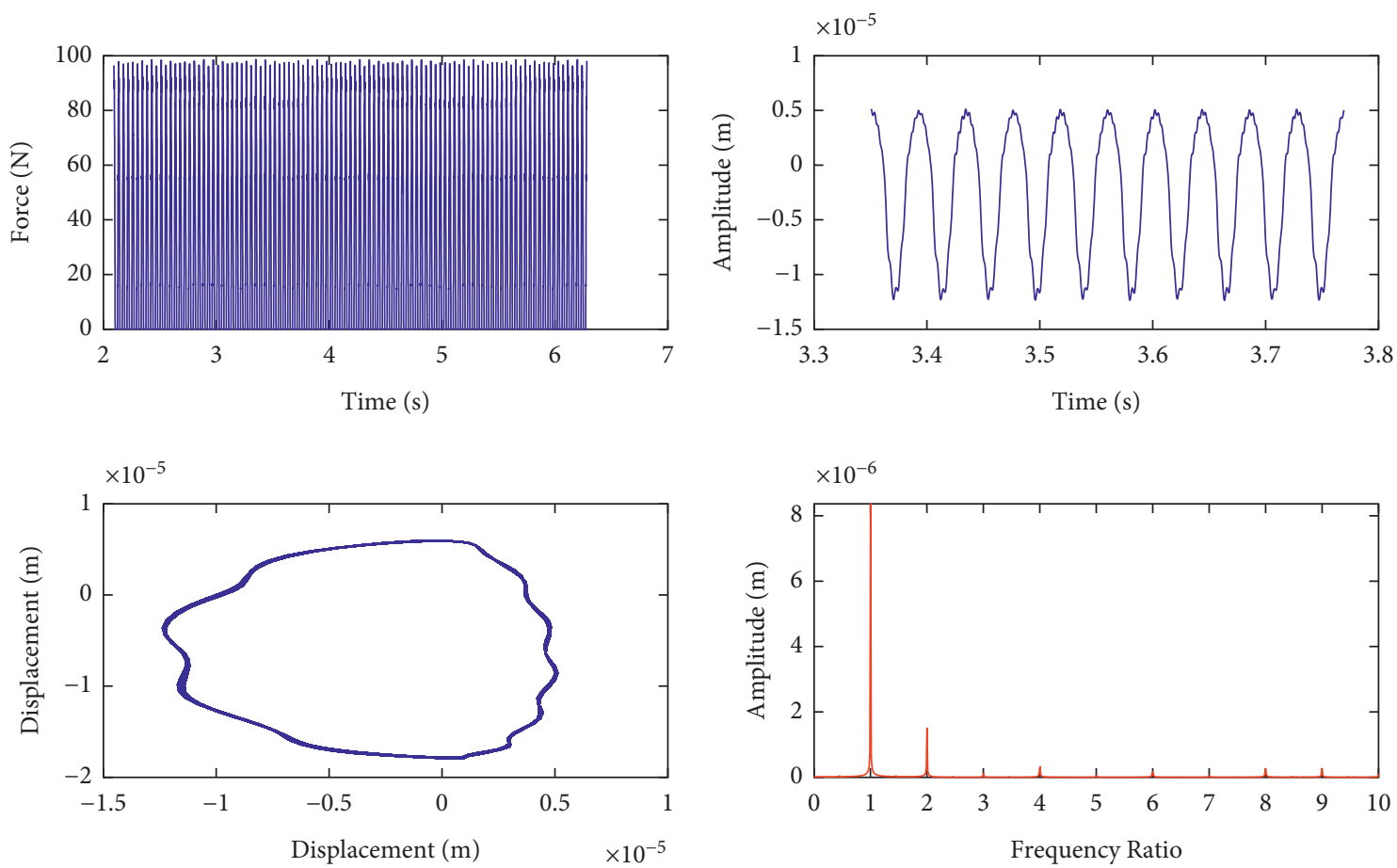

(a)
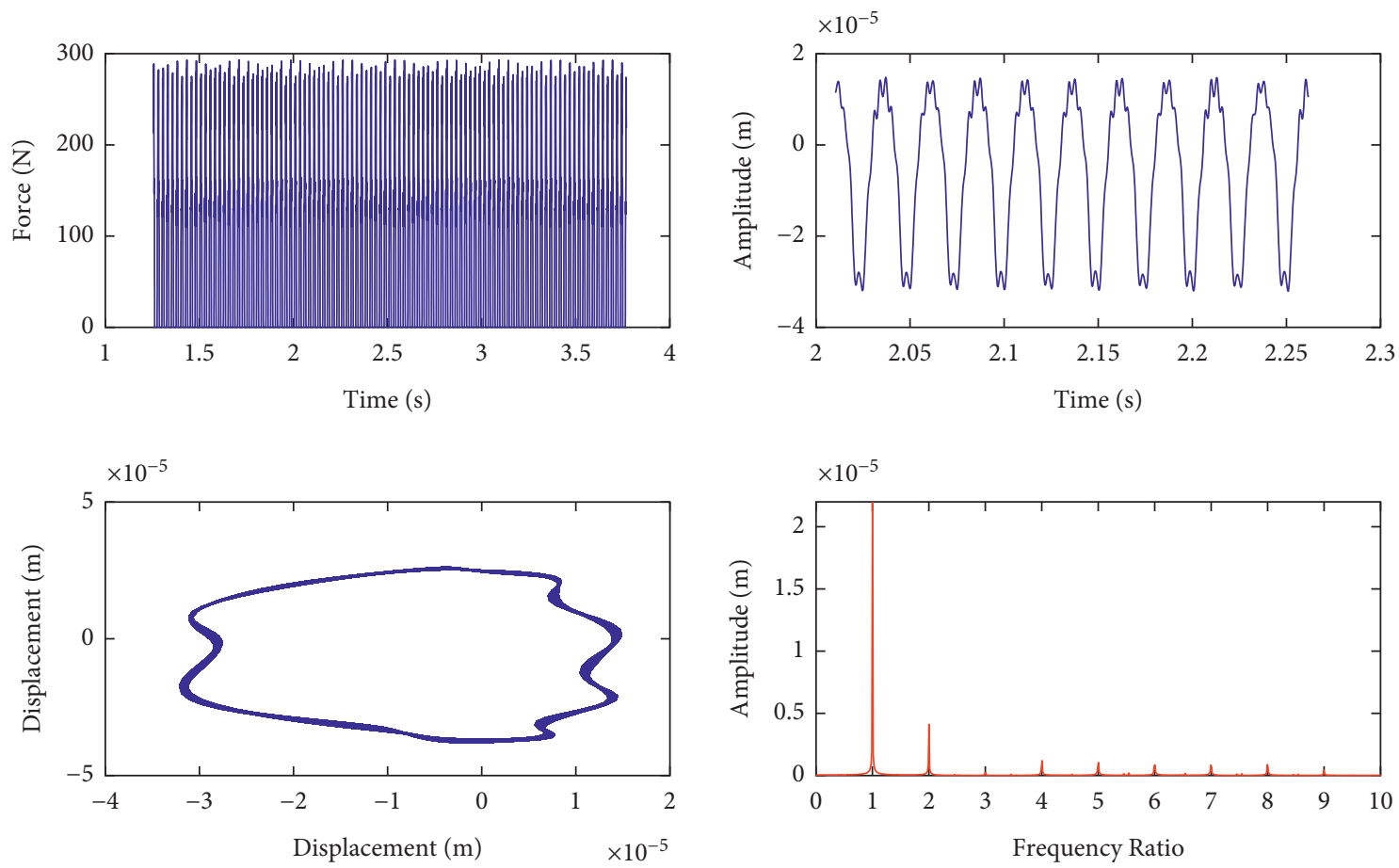

(b)

Figure 9: Continued. 

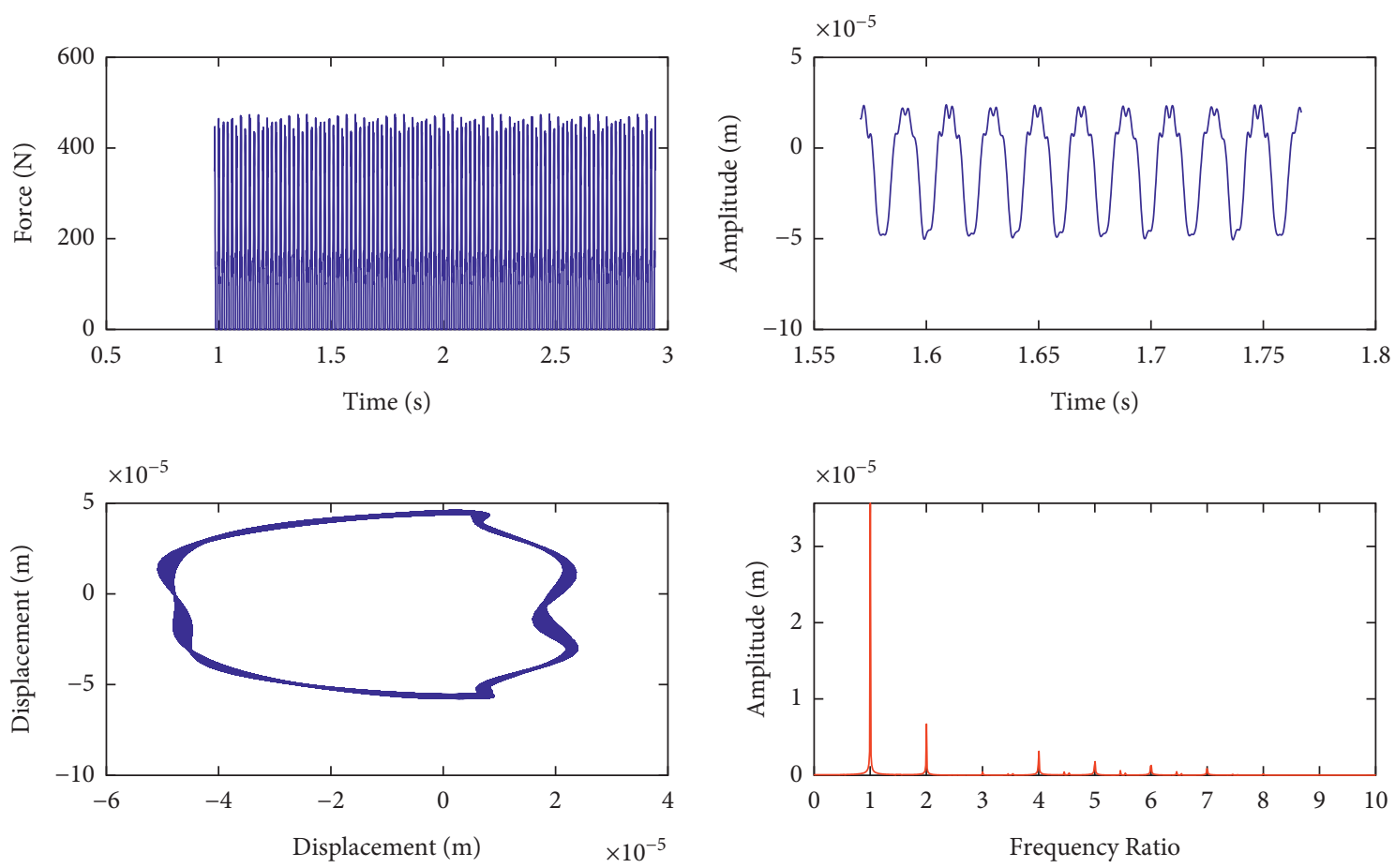

(c)
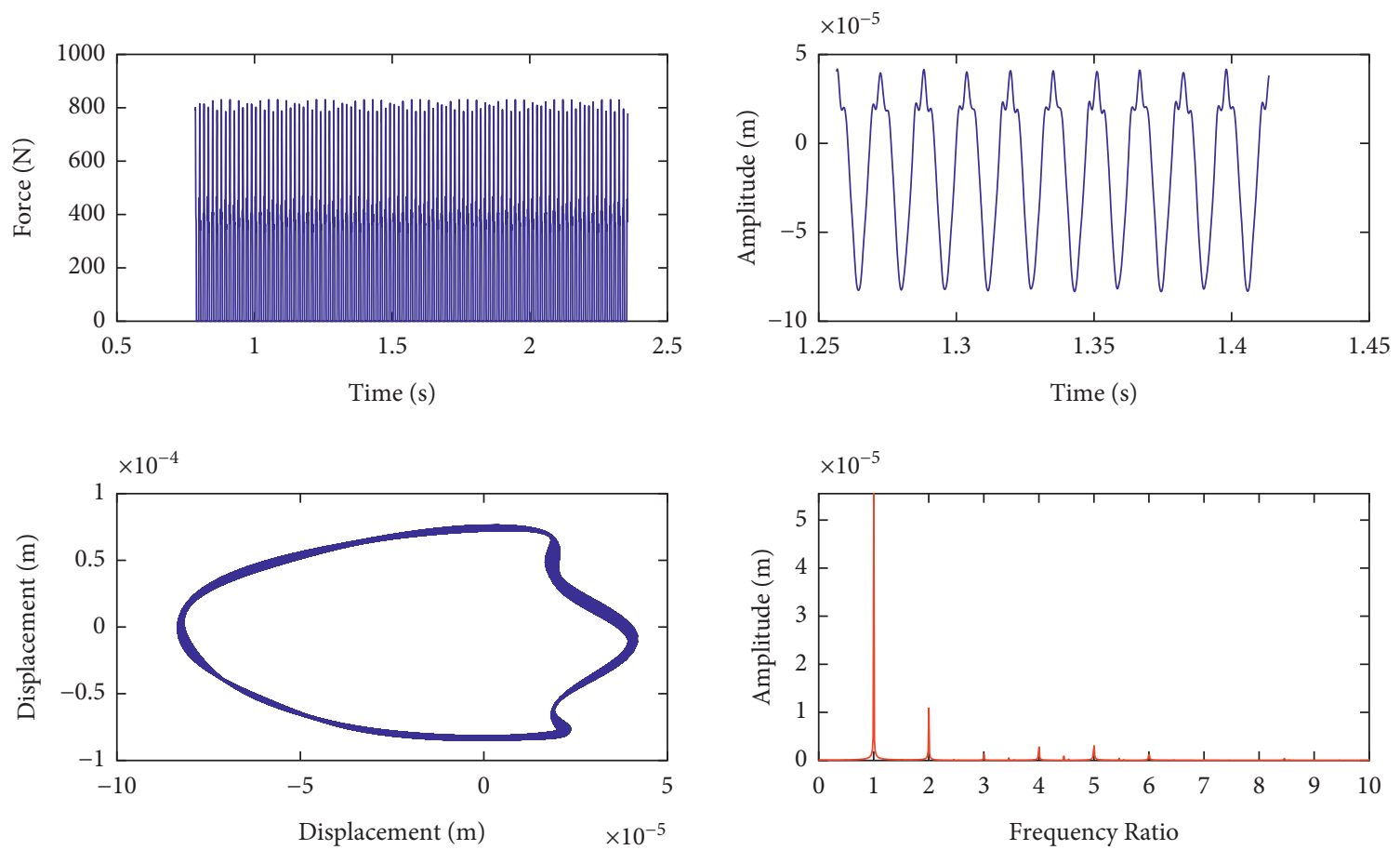

(d)

Figure 9: Vibration response of the blade-coating rubbing system at different speeds between blade tip and casing: (a) speed $150 \mathrm{rad} / \mathrm{s}$; (b) speed $250 \mathrm{rad} / \mathrm{s}$; (c) speed $320 \mathrm{rad} / \mathrm{s}$; (d) speed $400 \mathrm{rad} / \mathrm{s}$.

was introduced to control the clearance between the blade and casing. This device can adjust the incursion depth leading to the blade and casing rubbing with abradable coating. The blades were mounted on the disk by rivet connection.
The M601 AlSi-ployphenyl ester abradable coating was on the surface of the stator; the coating was fabricated by plasma spraying and the preparation process is shown in Figure 12. The elastic modulus of abradable coating is measured by the beam bend test method, which is shown in 


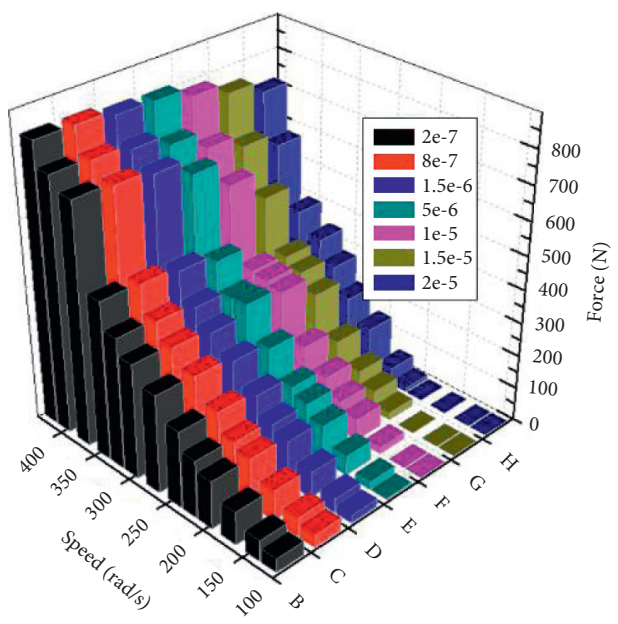

FIgURE 10: The rotor rubbing force at different clearances and speeds.

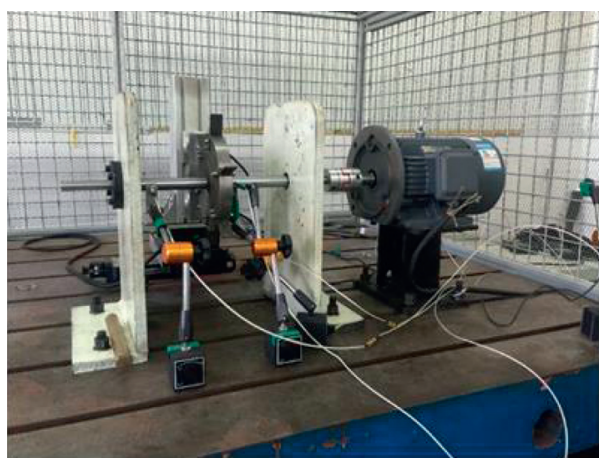

(a)

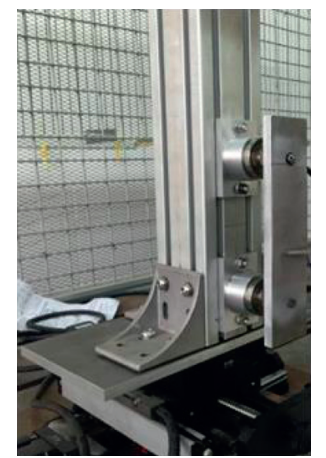

(b)

FIGURE 11: The experimental test. (a) The rubbing test bed of rotor system; (b) displacement station.
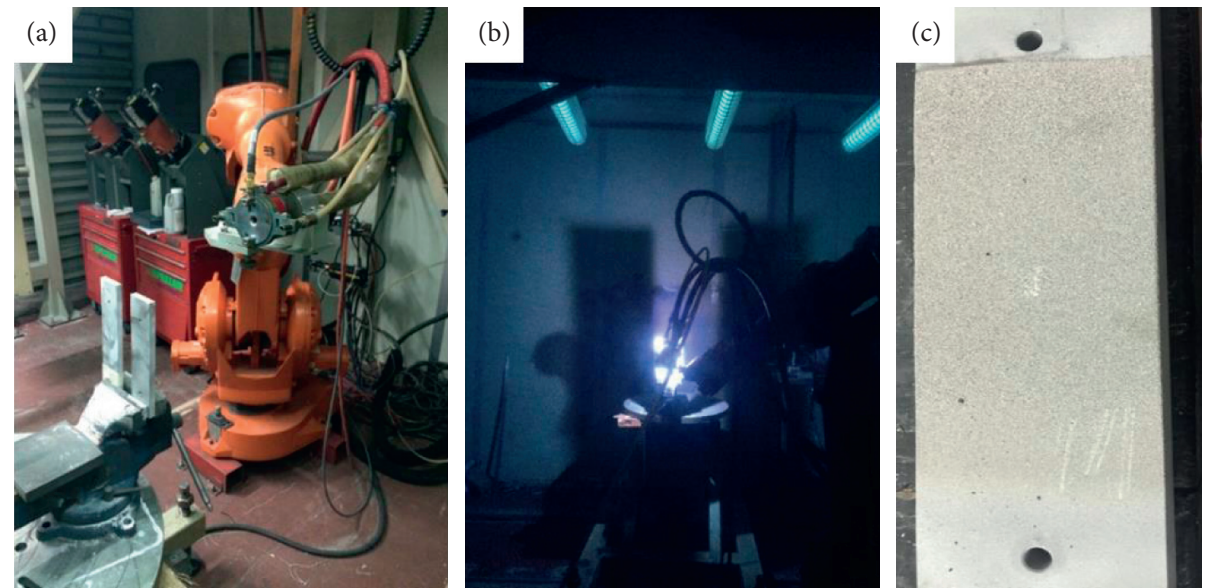

FIGURE 12: Plasma coating spraying equipment and postsprayed rubbing panels. (a) Plasma spraying equipment. (b) Spraying equipment at work. (c) Rubbing plate with coating.

Figure 13. The result is shown in Table 1. The thick layer of abradable coating is $1.5 \mathrm{~mm}$; in order to avoid direct contact between the blade and stator, the cumulative incursion depth is less than $1.2 \mathrm{~mm}$.
The max incursion depth is decreased linearly with the development of blade-casing clearance, as shown in Figure 14. At the beginning of the experiment, adjust the feeding device to make the stator contact with the rotating 


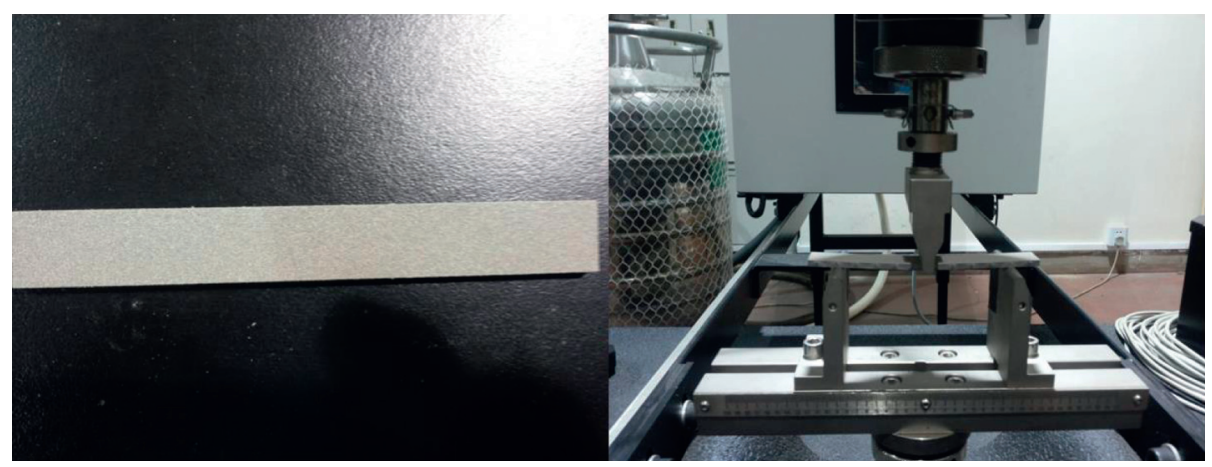

Figure 13: The measurement experiment of abradable coating elastic modulus.

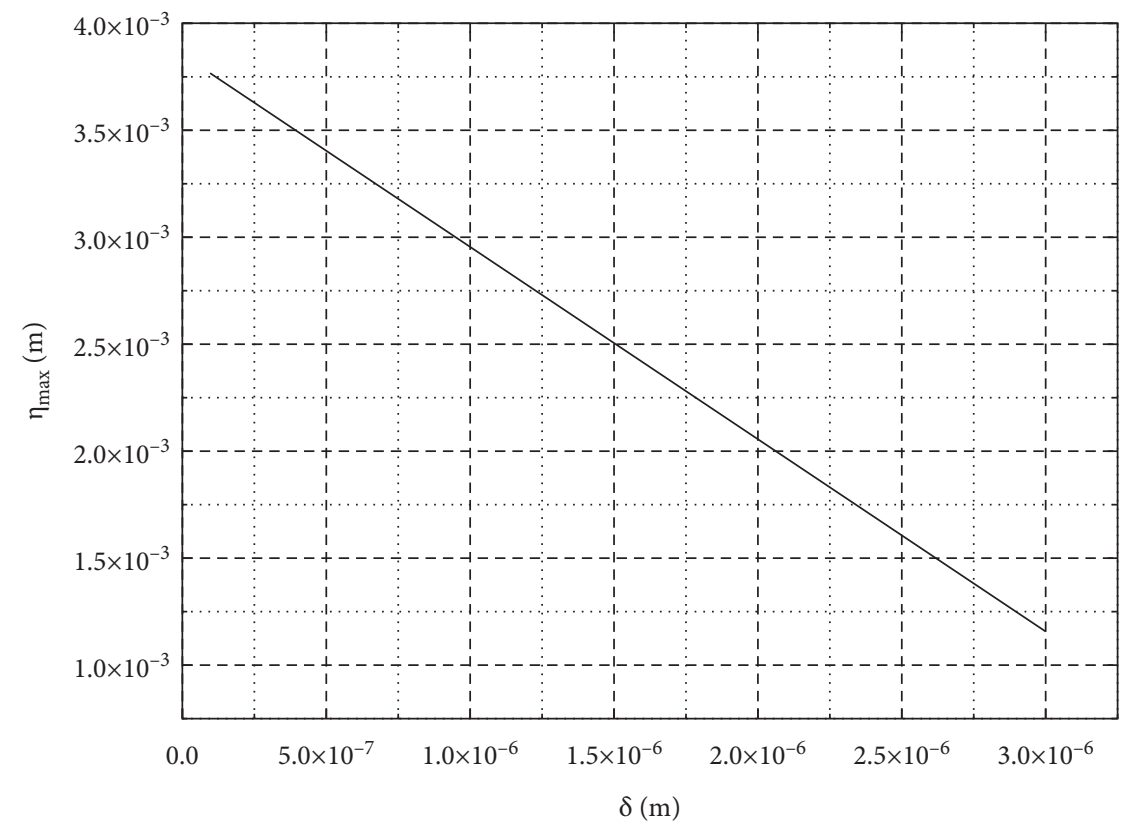

Figure 14: Relationship of the max incursion depth and clearance.

blade. When the system is stable, feed the stator and make the friction occur. Collect the friction signals under different invasion depths. The smaller the initial gap between the blade tip and the coating, the greater the corresponding invasion depth. In this experiment, the intrusion depth variable are at $0.1 \mathrm{~mm}, 0.2 \mathrm{~mm}, 0.3 \mathrm{~mm}$, and $0.4 \mathrm{~mm}$. The rubbing force and frequency amplitude are analyzed to verify the model. After the experiment, the maximal scraping depth of abradable coating is measured by the measuring laser microscope.

\subsection{Result and Discussion of Blade-Coating Rubbing} Experimental. Figure 15 shows the rubbing plate after rubbing experiment; distinguishing from the rotor-stator rubbing, obvious scraping phenomenon on the surface coating of rub impact plate is found.

Figure 16 shows the vibration response of blade-coating rubbing under different incursion depths. Figure 17 shows the variation of the frequency amplitude. It is shown that the fundamental frequency amplitude decreased from $33.73 \mu \mathrm{m}$

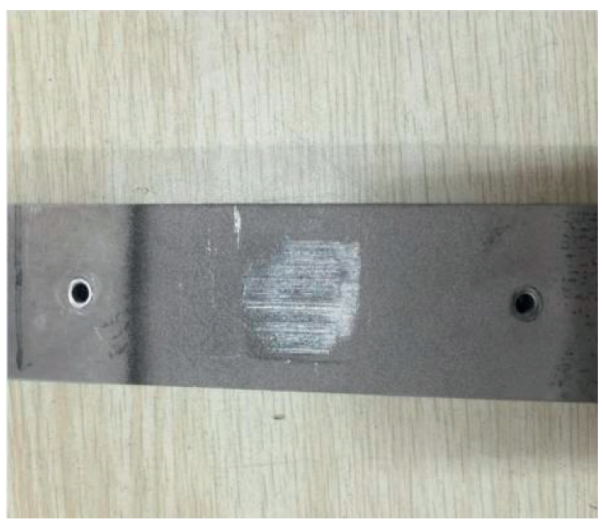

FIGURE 15: The rubbing plate with abradable coating after rubbing experiment.

to $24.01 \mu \mathrm{m}$. With the increase of intrusion depth, more frequency divisions appear on the spectrum, especially between 0 and fundamental frequency. The amplitude of 2fundamental frequency increases from $2.087 \mu \mathrm{m}$ to $3.76 \mu \mathrm{m}$. 

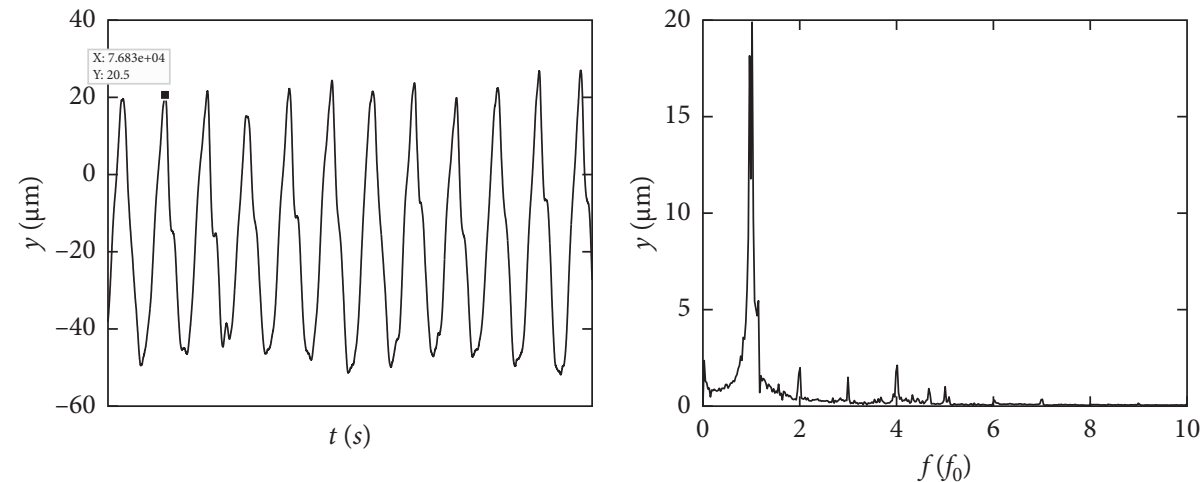

(a)
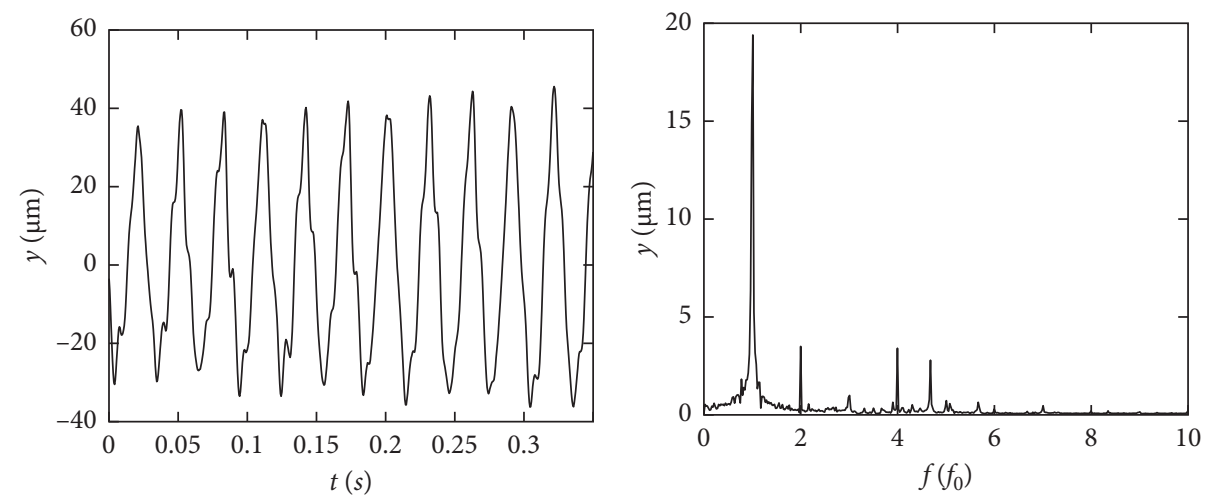

(b)
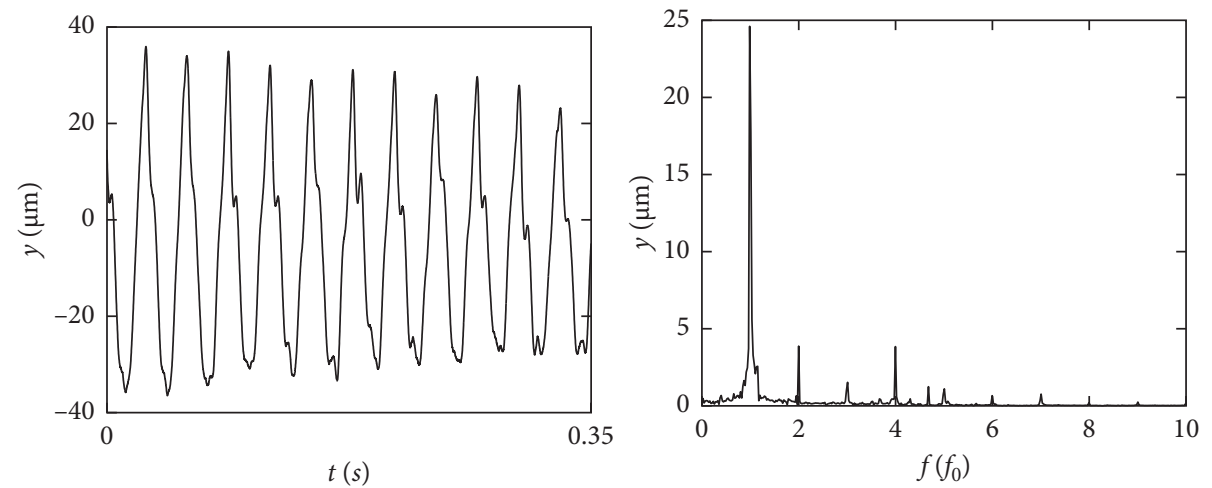

(c)
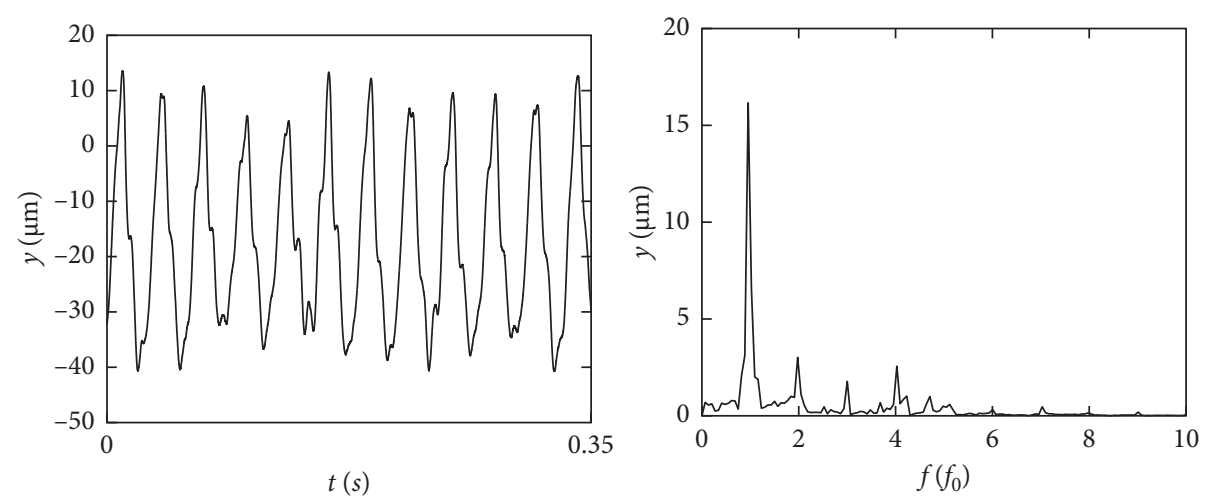

(d)

FIGURE 16: Vibration response of the blade-coating rubbing experimental results at different incursion depths. (a) Incursion depth $0.1 \mathrm{~mm}$. (b) Incursion depth $0.2 \mathrm{~mm}$. (c) Incursion depth $0.3 \mathrm{~mm}$. (d) Incursion depth $0.4 \mathrm{~mm}$. 


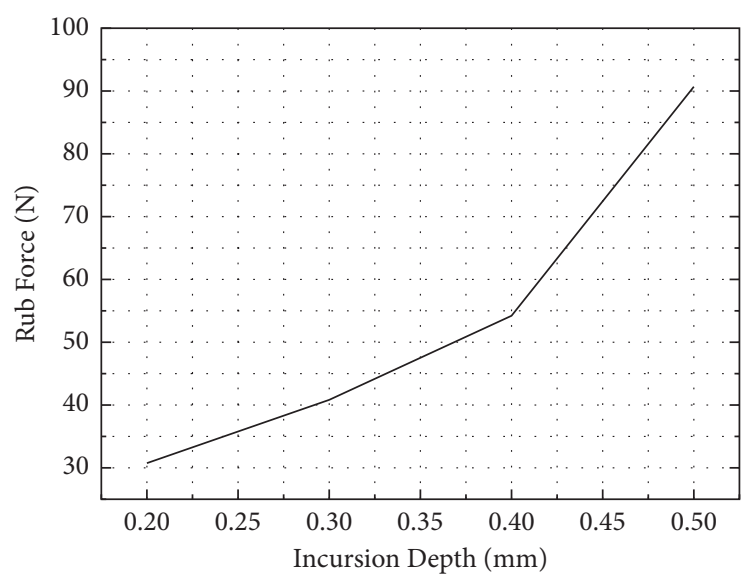

FIgURE 17: The rotor rubbing force at incursion depth.

The amplitude of 3-fundamental frequency decreases overall, but with a little fluctuation in this process. 4- and 4.68-fundamental frequency amplitudes increase with the development of incursion depth, and 5-and 6-fundamental frequency amplitudes are fluctuant with the development of incursion depth. The frequency and rubbing force variation law in the experiment is similar to the simulation results, but there are some differences between the simulation and experiment. Comparing Figures 10 to 17 , it is found that the maximal rubbing force increases almost linearly with the incursion depth increasing. Simulation and experimental results of rubbing force are consistent. It is found that the maximal scraping depth of abradable coating is obviously different with the incursion depth, which may affect the degree of blade-casing rubbing fault.

\section{Conclusion}

A force model of blade-coating rubbing is developed in this paper, which is on the basis of abradable coating scraping process analysis and considers the abradable coating characteristics and the interaction of blade and abradable coating. An experimental tester is established to verify the simulation. In the experiment, the AlSi-ployphenyl ester abradable coating is used, which is fabricated by plasma spraying. After the simulation and experiment, some conclusions are summarized as follows:

(1) For the blade-coating rubbing with abradable coating, the vibration of the rotor system is very complicated. The vibrations at integer harmonic frequencies (such as the fundamental frequency and the multiple fundamental frequencies) are produced during the blade-coating rubbing with the abradable coating. The clearance deeply affects the dynamic characteristics of blade-coating rubbing system. The fundamental frequency amplitude is increased by the clearance development. The 2-fundamental frequency and some multiple fundamental frequency amplitudes are decreased with the clearance increasing. The speed affects the fundamental frequency and 2-fundamental frequency more than the multiple high fundamental frequencies.
(2) The nonlinearity of the rubbing force increases rapidly with the increase of the rotating speed at the same clearance; the increase amplitude is also increased with the speed development. At the same speed, the rubbing force increases slowly and linearly with the increase of the initial clearance, the rubbing force has different variation laws on clearance at different speeds. The comparative analysis shows that the variation law of the peak value of the rubbing force is similar to that of the high multiple integer frequencies. Therefore, the main characteristic frequencies of blade seal coating rubbing are high multiple integer frequencies which are deeply affected by rubbing force. At high speed, the unbalance of the system is dominant and the rub impact characteristics have little influence.

(3) In the blade-coating rubbing experimental, the obvious material removal phenomenon on the surface coating of rub impact plate is found. The maximal scraping depth of abradable coating is obviously different with the incursion depth, which may affect the degree of blade-casing rubbing fault. The experimental results show that the model can comparatively accurately describe the blade-coating dynamic characteristics. The different phenomenon in experiment means the material properties of abradable coating may be an interesting study point in the future research of blade-coating rubbing.

\section{Data Availability}

The data used to support the findings of this study are available from the corresponding author upon request.

\section{Conflicts of Interest}

The authors declare that they have no conflicts of interest.

\section{Acknowledgments}

This work was financially supported by the project supported by the Joint Funds of the National Natural Science Foundation of China (U1933202) and project supported by the Fundamental Research Funds for the Central Universities of Ministry of Education of China (3122019091).

\section{References}

[1] A. Millecamps, A. Batailly, M. Legrand, and F. Garcin, "Snecma's viewpoint on the numerical and experimental simulation of blade-tip/casing unilateral contacts," in Turbo Expo: Power for Land, Sea, and AirAmerican Society of Mechanical Engineers (ASME), New York, NY, USA, 2015.

[2] N. Salvat, A. Batailly, and M. Legrand, "Modeling of abradable coating removal in aircraft engines through delay differential equations," Journal of Engineering for Gas Turbines and Power, vol. 135, no. 10, Article ID 102102, 2013.

[3] Z. Lu, S. Zhong, H. Chen, Y. Chen, J. Han, and C. Wang, "Modeling and dynamic characteristics analysis of blade-disk 
dual-rotor system," Complexity, vol. 2020, Article ID 2493169 , 13 pages, 2020.

[4] H. Ma, F. Xie, H. Nai, and B. Wen, "Vibration characteristics analysis of rotating shrouded blades with impacts," Journal of Sound and Vibration, vol. 378, pp. 92-108, 2016.

[5] X. Guo, J. Zeng, H. Ma, C. Zhao, X. Yu, and B. Wen, "A dynamic model for simulating rubbing between blade and flexible casing," Journal of Sound and Vibration, vol. 466, Article ID 115036, 2020.

[6] G. F. Nan, "Modeling and dynamic analysis of shrouded turbine blades in aero-engine," Journal of Aerospace Engineering, vol. 29, Article ID 04015021, 2020.

[7] G. Chen, "Simulation of casing vibration resulting from bladecasing rubbing and its verifications," Journal of Sound and Vibration, vol. 361, pp. 190-209, 2016.

[8] H. Ma, X. Tai, Q. Han, Z. Wu, D. Wang, and B. Wen, “A revised model for rubbing between rotating blade and elastic casing," Journal of Sound and Vibration, vol. 337, pp. 301-320, 2015.

[9] F. Nyssen and A. Batailly, "Thermo-mechanical modeling of abradable coating wear in aircraft engines," Journal of Engineering for Gas Turbines \& Power, vol. 141, no. 2, 2019.

[10] W. Xue, S. Gao, D. Duan, J. Zhang, Y. Liu, and S. Li, "Effects of blade material characteristics on the high-speed rubbing behavior between Al-hBN abradable seal coatings and blades," Wear, vol. 410-411, pp. 25-33, 2018.

[11] B. Martinet, A. Cappella, S. Philippon, and C. Montebello, "Effect of temperature on wear mechanisms of an aluminium - based abradable coating for aircraft engines after a dynamic interaction with a Ti6Al4V blade," Wear, vol. 446-447, Article ID 203202, 2020.

[12] A. Batailly, M. Legrand, A. Millecamps, and F. Garcin, "Numerical-experimental comparison in the simulation of rotor/stator interaction through blade-tip/abradable coating contact," Journal of Engineering for Gas Turbines \& Power, vol. 134, no. 8, 2012.

[13] A. Batailly and M. Legrand, "Conjectural bifurcation analysis of an aircraft engine blade undergoing 3D unilateral contact constraints," in Proceedings of the ASME Turbo Expo 2014: Turbine Technical Conference and Exposition, Düsseldorf, Germany, June 2014.

[14] A. Batailly, M. Legrand, A. Millecamps, S. Cochon, and F. Garcin, "Redesign of a high-pressure compressor blade accounting for nonlinear structural interactions," Journal of Engineering for Gas Turbines \& Power, vol. 137, no. 2, 2014.

[15] P. Almeida, C. Gibert, F. Thouverez, X. Leblanc, and J.-P. Ousty, "Numerical analysis of bladed disk-casing contact with friction and wear," Journal of Engineering for Gas Turbines \& Power, vol. 138, no. 12, 2016.

[16] N. Olgac, U. Zalluhoglu, and A. S. Kammer, "On blade/casing rub problems in turbomachinery: an efficient delayed differential equation approach," Journal of Sound and Vibration, vol. 333, no. 24, pp. 6662-6675, 2014.

[17] Q. Agrapart, F. Nyssen, D. Lavazec, P. Dufrénoy, and A. Batailly, "Multi-physics numerical simulation of an experimentally predicted rubbing event in aircraft engines," Journal of Sound and Vibration, vol. 460, Article ID 114869, 2019.

[18] J. Zhang, X. Lu, J. Lin, L. Ma, and J. Wang, "Dynamic analysis of a rotor-bearing-SFD system with the bearing inner race defect," Shock and Vibration, vol. 2017, Article ID 2489376, 13 pages, 2017.

[19] A. F. Kascak and J. J. Tomko, "Effects of different rub models on simulated rotor dynamics," National Aeronautics And
Space Administration Cleveland Oh Lewis Research Center, Washington, DC, USA, NASA-E-1801, 1984.

[20] M. Z. Yi, X. L. Zhang, N. S. Hu, and J. W. He, "Abradability evaluation of seal coating by impact-scraping test machine," Acta Aeronautica et Astronautica Sinica, vol. 20, no. 3, pp. 249-253, 1999, in Chinese.

[21] K. Ding, Z. Wang, X. Lu, J. Zhang, and L. Ma, "Vibration investigation of rotor system with unbalance and blade-casing rubbing coupling faults," Journal of Vibroengineering, vol. 22, no. 2, pp. 353-365, 2020. 